\title{
THE ROLE OF ASCE IN THE ADVANCEMENT OF COMPUTING IN CIVIL ENGINEERING
}

\author{
Steven J. Fenves, Hon. Mem. ASCE \\ William J. Rasdorf, P.E., F. ASCE
}

\begin{abstract}
Computing has emerged as a major focus area in civil engineering, just as it has in other disciplines. This paper examines the role of ASCE in the advancement and development of this focus on computing in civil engineering. The paper documents the technical activities of ASCE that contributed to this evolution, particularly the committees of the Structural Division (now the Stuctural Engineering Institute) and the Technical Council on Computer Practices (now the Technical Council on Computing and Information Technology). Emphasis is placed on the initial activities and the current status of each group. A broad survey of ASCE activities that contribute to the dissemination of information on computing in civil engineering is presented. The role of ASCE publications in this effort is examined. The ASCE conferences and congresses on computing are documented and evaluated. Finally, observations are made about the Society's overall impact on computing in civil engineering.
\end{abstract}

\section{KEY WORDS}

ASCE

Structural Division

Structural Engineering Institute

Computing in Civil Engineering

Computer Aided Design

Computer Aided Engineering

Journal of Computing in Civil Engineering

Research Council on Computing Practices

Structural Division

Structural Engineering Institute

Technical Council on Computing Practices

Technical Council on Computing and Information Technology 


\title{
THE ROLE OF ASCE IN THE ADVANCEMENT OF COMPUTING IN CIVIL ENGINEERING
}

\author{
Steven J. Fenves, Hon. Mem. ASCE \\ William J. Rasdorf, P.E., F. ASCE
}

\begin{abstract}
Computing has emerged as a major focus area in civil engineering, just as it has in other disciplines. This paper examines the role of ASCE in the advancement and development of this focus on computing in civil engineering. The paper documents the technical activities of ASCE that contributed to this evolution, particularly the committees of the Structural Division (now the Stuctural Engineering Institute) and the Technical Council on Computer Practices (now the Technical Council on Computing and Information Technology). Emphasis is placed on the initial activities and the current status of each group. A broad survey of ASCE activities that contribute to the dissemination of information on computing in civil engineering is presented. The role of ASCE publications in this effort is examined. The ASCE conferences and congresses on computing are documented and evaluated. Finally, observations are made about the Society's overall impact on computing in civil engineering.
\end{abstract}

\section{INTRODUCTION}

Computers and computer-based tools have been an integral part of civil engineering for nearly fifty years. Much of today's civil engineering practice, particularly its reliance on rapid communication and interaction, on analytical modeling and simulation, and on geometric modeling and visualization, would be inconceivable without the aid of computing. A great deal of the computing underlying civil engineering practice and research has become so routine that it is simply not reported. Innovations, research results, and new developments based on computing capabilities tend to be reported in the conferences and journals of the appropriate sub-discipline within civil engineering most directly affected: structures, water resources, transportation, construction, and the like.

Paralleling and, to an extent, integrating the discipline-specific advances there has emerged a broad, discipline-wide emphasis on the rapid evolution of computing, its supporting basic sciences, and its enabling information technologies. This emphasis is coupled to the exploration of potentials for improving civil engineering research, education, and practice by the exploitation of the emerging developments. In this paper, computing is used in its broadest sense to include computer-based communication, sharing and display of graphical, textual and symbolic information and reasoning as well as calculation on numeric data. Computing thus defined affects every sphere of human endeavor. This paper specifically addresses computing in civil engineering. 
The paper provides a compilation and review of a portion of the historical record of computing in civil engineering. This historic review is not meant to be complete and comprehensive. Rather, it is intended to sketch the evolution of those aspects of computing in civil engineering that have shaped today's roles and perceptions. The review is highly idiosyncratic, reflecting the authors' experiences, or rather, their memory of those experiences, supplemented with material from the authors' files and contributions from colleagues. Furthermore, the review concentrates largely on the role of ASCE and its technical activities, conferences, and publications as a window on the evolution of the profession's practical, educational, and research activities in computing, rather than on the activities themselves.

The paper includes some new compilations of data on computing in civil engineering. It also summarizes and refers to other resources where more complete compilations of information already exist. Thus, it is intended to serve as a starting point for understanding the evolution of computing in civil engineering.

The activities and events described were the result of the work of many ASCE members. The authors wish that they had the space to acknowledge the contributions of all of these dedicated volunteers, but due to space limitations they had to restrict themselves to recognizing only the most salient participants. The authors apologize in advance to those whose work could not be individually recognized.

\section{ORGANIZATION OF PAPER}

This section provides a brief introduction to the organization of the paper.

The Early History of Computing in Civil Engineering Section discusses the first steps in the introduction of computing into the civil engineering profession. The section describes the earliest civil engineering computing applications and identifies early difficulties and inhibitions to computing. The emergence, and subsequent disappearance, of user groups are described.

$A S C E$, the leading professional society of civil engineers, has played a significant role in the evolution of computing in civil engineering. This section examines what that role has been and what it is today. It identifies those ASCE activities that have had the most significant role in shaping computing and its use in civil engineering.

The ASCE Journal of Technical Topics (hereinafter referred to as the JTT) was one of the earlier journals to focus on computing in civil engineering. It was followed by the ASCE Journal of Computing in Civil Engineering (JCCE). The Publications Section examines what has been published in these and other related journals. Some trends are identified and the more recent shifts in computing in civil engineering directions are identified. Other Society publications are examined as well.

The Summary and Observations Section provides a synthesis of ideas and frames a window on the profession's use of computing and ASCE's overall impact on it. 


\section{EARLY HISTORY OF COMPUTING IN CIVIL ENGINEERING}

Civil engineers began to use computers quite early. The two major impetuses for the introduction of computing in the 1950's and 60's were, first, the defense and space programs and, second, the interstate highway system. Defense and space efforts required a whole new range of structural response modeling capabilities, while the vast interstate construction program required extensive design calculations at an enormous scale. Without a doubt, the single most successful civil engineering application of the early decades was the earthwork quantity ("cutand-fill") calculation program, churning out daily earthwork volumes for miles and miles of highways without having to draw and measure by planimeter the cross-sections at every station. Optimization, in the sense of balanced cut and fill, became a practical reality by re-running the calculations with changed grade elevations. The program further doubled its usefulness, thus establishing the principle of capturing data at the source, when it began to be used not just for design ("estimated quantities") but also for computing payments to contractors ("final quantities") using the original ground data in conjunction with the final survey results.

The first computers acquired by engineering organizations, whether public agencies or private consulting and construction firms, came with some rudimentary programming tools - either native machine or assembly languages or not much more effective interpreted systems - and essentially no software. Thus, civil engineering organizations faced the daunting task of programming all the applications they needed.

Not surprisingly, user groups were quickly formed in order to share development efforts as well as to provide a united voice to the hardware vendors, particularly in clamoring for better software development tools. User groups tended to cluster around particular brands of computers, such as the Bendix G-15, the LGP30, and the IBM 650 and 1620 (all long ago consigned to their welldeserved trash-piles). User groups sharing application interests began exchanging programs, tentatively and haphazardly at first, becoming better organized as time progressed, with coordinated planning, explicit development responsibilities, and elaborate accounting schemes for credits earned by submitting programs.

The IBM 1130, introduced around 1960 with the first practical FORTRAN compiler for small computers, became popular with civil engineering firms, and eventually the 1130 Users' Group, renamed CEPA (formed in 1965; the acronym initially stood for Civil Engineering Program Applications, and was retained after the group was incorporated as the Society for Computer Applications in Engineering, Planning and Architecture), became the preeminent civil engineering user organization [CEPA 66]. In response to CEPA demands for a structural analysis tool, IBM provided a version of STRESS [Fenves 64, 65] for the 1130. A second user group, HEEP (Highway Engineering Exchange Program), attracted state transportation departments as well as their consultants. Many firms belonged to both groups. Somewhat later, the ICES (Integrated Civil Engineering System [Roos 66, 67]) User Group (IUG) became another user organization, notable in that it was concerned not with program development, but with the maintenance and use of ICES and its constituent programs, particularly STRUDL [Logcher 65], an outgrowth of STRESS, and COGO [Miller 61, Roos 64]. 
Eventually, professional issues related to the cost of computer program development, charging policies for computer use, and legal responsibilities began to dominate discussions at user group meetings. CEPA and similar groups felt that they needed representation at a higher professional level than provided by their separate organizations. As discussed below, CEPA members were subsequently influential in directing ASCE into activities dealing with professional practice.

As computing in civil engineering practice increasingly moved away from in-house software development towards acquired third-party software, the role of user groups diminished substantially. In retrospect, it is difficult to determine how effective the actual program exchange function of these organizations was. Essentially all programs acquired from external sources had to be modified to some degree to reflect local practices. Suites of inter-related programs developed by a number of organizations did not mesh as well as planned. The primary intangible benefit of membership in the user groups turned out to be the networking the groups provided, binding together a collection of civil engineering computing professionals who were aware of the pioneering work they were doing.

\section{ASCE}

The Divisions within ASCE that have been most active in computing in civil engineering are the Structural Division and the Technical Council on Computing and Information Technology (TCCIT). These are discussed in detail in the following sections. Additionally, the current activities of all Institutes, Divisions, and Councils active in computing are also discussed.

\subsection{Structural Division}

\subsubsection{Initial Committee Activities}

The Structural Division's Committee on Electronic Computation was formed in the Fall of 1957. Its first chairman was Dr. Nathan M. Newmark, Head of the Department of Civil Engineering at the University of Illinois, a pioneering researcher and educator in structural engineering. The contact member from the Executive Committee of the Division was Dr. Elmer Timby, a distinguished educator and consultant. It undoubtedly required the prestige of these two gentlemen to convince the Division to establish a committee devoted to a device that was then still considered largely a laboratory curiosity. In the initial round of correspondence about potential committee activities, one member suggested the task of "Keeping a record of civil engineers in this country who are actively doing work in this field of Electronic Computation." Had such a record been implemented, it would have contained a few hundred entries, at most. Fenves, then a graduate student and Instructor at the University of Illinois was made secretary of the Committee.

The initial subcommittees established by the Committee on Electronic Computation were:

- Programming and Coding

- Mathematical Methods

- Data Processing

- Current Progress and Planning 


\section{- Publications and Technical Programs}

The first subcommittee eventually produced a series of Manuals (the first Manual starting with machine language programming, of course, before proceeding to index registers) and the second a number of annotated bibliographies, comparative book reviews, and program feature comparisons. In very short order, however, the Publications and Technical Programs subcommittee became the primary focus of the Committee, starting with the organization of the first session on computing at the February 1958 ASCE Convention in Chicago. Dr. Elvind Hognestad, the Technical Program Committee chairman for the Convention, asked the Committee to provide "a broad, simple, and informative subject presentation designed to be a 'first meeting' of the civil engineer of the audience with a new tool, the digital computer, which has the future potentiality of becoming as important to him as the slide rule." Fenves recalls the subcommittee rounding up the first three speakers, all Ph. D.'s, and then working hard to find a fourth speaker who did not have an advanced degree, reflecting the subcommittee's strong belief that eventually it would not be necessary to have a $\mathrm{Ph}$. D. to be able to write a civil engineering application program.

Starting with Kansas City in 1958, the Committee organized a series of Conferences on Electronic Computation that have continued to this day (see Appendix A). Papers presented at the early Conferences dealt with a great variety of analysis and design methods and programs; others addressed important issues of the day, such as analyzing very large structures on computers with 1 to $2 \mathrm{~K}$ words of memory (that is kilobytes, not megabytes) and setting up early users' groups. Many other papers had impacts that are still felt today: the first matrix and finite element analysis papers by Ray Clough [Clough 58, 60], the first consistent mass matrix paper by John Archer [Archer 63], and others. The successive conference technical program committees exercised stringent quality control on the papers accepted. As an example, following C. L. Miller's paper on "Man-Machine Communication" at the $3^{\text {rd }}$ Conference [Miller 63] (apologies for the gender insensitivity of the time), papers describing programs that depended on users providing numeric codes for selecting program options were summarily rejected.

As time progressed, the Committee attempted to address a range of issues broader than structural analysis and design. A subcommittee on Professional Problems was formed in 1967 and one on Interdisciplinary Activities in 1970. Such activities were viewed as exceeding the scope of the Structural Division within ASCE, and some had to be curtailed or eliminated at the request of the Division's Executive Committee. As a result, some Committee members began to look for alternate means of action within the Society's framework.

In retrospect, from the mid-1950's to the mid-1970's the Structural Division's Committee on Electronic Computation, chaired in succession by Nathan M. Newmark, Sidney Shore, Robert E. Fulton, and Donald McDonald, reflected quite accurately the developments of computing as they related to the technical aspects of structural engineering. Its conference proceedings and other publications showed the profession's response to the rapid, if not revolutionary, changes in support technologies such as programming languages, hardware and communication technologies, new application areas such as CAD and computer graphics and in research leading to new modeling and analysis capabilities. The Committee's position within the ASCE 
organizational structure made it unsuited to address professional issues transcending structural engineering and affecting a larger proportion of the Society's members.

\subsubsection{Current Committee Activities}

The Structural Division has since evolved into the Structural Engineering Institute. The Committee on Electronic Computation has continued to function to this day. Following the $10^{\text {th }}$ Conference on Electronic Computation in 1991, the Committee was renamed the Committee on Analysis and Computation in 1992. Its activities are summarized in Section 4.2.2 below.

Over a span of 33 years, from 1958 to1991, the Structural Division sponsored 10 Conferences on Electronic Computation (see Appendix A), averaging one approximately every 3 years. The $3^{\text {rd }}$, $4^{\text {th }}, 5^{\text {th }}$, and $6^{\text {th }}$ conferences were republished as special issues of the Journal of the Structural Division. The $11^{\text {th }}$ through $14^{\text {th }}$ Conferences on Analysis and Computation (sponsored by the Structural Engineering Institute) have been offered on a two-year cycle. The primary focus of these conferences is on computing in structural engineering.

\subsection{Other Divisions}

\subsubsection{Initial Committee Activities}

Progressions very similar to that of the Structural Division took place in other Divisions. Specifically, by the late 1960's the Geotechnical and Hydraulics Divisions both had technical committees similar in scope to the Committee on Electronic Computation of the Structural Division, although with less aggressive schedules of publications and specialty conferences. Contact among these groups across Divisions was either through personal contacts or through organizations external to ASCE.

\subsubsection{Current Committee Activities}

Today ASCE members are involved in computing through committee activities in a number of Divisions. The following is a list of the ASCE committees specifically involved in computing [ASCE 00] and their purposes.

Urban Transport Division, Computing in Transportation Committee.

Purpose: to facilitate dissemination of information on new developments in computing for planning, design, operations, and management of urban transportation systems. The committee will encourage education and research necessary to advance computing applications in academia and practice.

Geo Institute, Computer Applications and Numerical Methods Committee.

Purpose: to serve the geo-profession areas of general computing use including 1) software availability, 2) information technology, 3) numerical methods, and 4) general computing issues in professional practice. The committee provides support in these areas both in leading roles as well as in cooperation with other technical committees and organizations. 
Construction Division, Computing in Construction Committee.

Purpose: to stimulate and influence the effective application of computer technology in construction.

Geomatics Division, Geographic Information Systems Committee.

Purpose: to serve as a resource to the profession in providing recommended guidelines for development and selection of processes, procedures, techniques, and technologies associated with the collection, management, dissemination and utilization of spatially related data; to identify and formulate the responsibility and contribution of civil engineering to integrated geographic information systems; to foster studies, research and development; to develop and maintain appropriate technical standards and procedures; and to provide a focal point for interdivisional and interdisciplinary cooperation.

Structural Engineering Institute, Analysis and Computation Committee.

Purpose: to report, encourage development of, and evaluate innovative methods of structural analysis; to foster use of digital computer and other modern computing devices to obtain more effective analyses and improved designs, and to encourage the development and reporting of innovations in the use of computers that may have practical significance, and to report on professional problems involving multi-disciplinary use of computers.

Structural Engineering Institute, Emerging Computing Technology Committee.

Purpose: to provide a mechanism by which various emerging computing technologies that may be applicable to some part of the structural engineering process can be identified and brought to the attention of the structural engineering community. These technologies include parallel and distributed computing, databases and information systems, web-based and collaboration technologies, artificial intelligence, field based computing and automation.

\subsection{Research Council on Computer Practices}

In 1970, a group of CEPA members who were also members of ASCE petitioned the Society "to appoint a coordinating council to deal with the legal, professional and educational aspects of computer use, cutting across the technical divisions of ASCE." The initial petition brought the CEPA group in contact with like-minded people in the Structural and Geotechnical Divisions, and eventually led to the establishment of the Technical Council on Computer Practices via the short-lived Research Council on Computer Practices.

At the time the CEPA petition was made, Technical Councils were viewed within ASCE as proving grounds for fledgling Divisions. The Society had never before received a petition for a Council that clearly stated that the proposed Council had no intention of ever becoming a Division. As a result, the CEPA petition was denied. However, since research was one potential activity of such an eventual council, and since the Committee on Research was willing to act as a sponsor, the petition was changed to that for a Research Council on Computer Practices. The Task Committee on Computer Application Research of the Committee on Research was charged with organizing the Research Council and clarifying its relationship to an eventual Council with broader goals. At its first meeting, the Task Committee resolved that "this group intends to be the focal point in studying and pursuing the establishment of a Computer Practices Council." 
The Research Council on Computer Practices was authorized in 1972 with Elias C. Tonias, a consulting engineer - later a software developer - and CEPA member, as Chair and Fenves as Vice-Chair. The Research Council proceeded to define the scope of the council-to-be in the following areas:

- Coordination within ASCE among the computing-related activities of the Divisions

- Coordination outside ASCE with professional and users groups

- Education

- Professional Practice

- Research

The aspects of Professional Practice of concern included:

- Computer pricing policies

- Computer facility organization and management

- Credibility and legal aspects of computer-aided-design

- Software development costs and recovery procedures

- Job description and salary structure

- Legal and professional aspects of program sharing

This latter list makes clear the ambitious scope of professional practice issues that awaited the attention of the proposed council-to-be, quite distinct from the technical issues addressed by committees of the technical divisions.

The Research Council on Computer Practices was abolished in 1973 as soon as the Technical Council on Computer Practices was authorized.

\subsection{Technical Council on Computer Practices}

\subsubsection{Initial Committee Activities}

As stated above, the first petition for a Technical Council on Computer Practices was denied because it was too broad in scope and cut across the traditional boundaries of the Technical Divisions. Coincidentally, while the second petition was being circulated in draft form, the ASCE Technical Activities Council (TAC), which oversees the divisions, was performing its own major restructuring study. The study group, chaired by Professor Albert D. M. Lewis, Professor of structural engineering at Purdue University, was considering a "matrix management" structure, with divisions representing the "depth" dimension and some other organizational form representing the "breadth" dimension. The draft petition was embraced by the restructuring study group, which recommended "Technical Council" as the designation of the groups dealing with the "breadth" dimension.

The Technical Council of Computer Practices (TCCP) was authorized on January 30, 1973, as the first council under the new TAC organization. Subsequently, four other Technical Councils were formed: Codes and Standards, Lifeline Earthquake Engineering, Research, and Cold 
Regions. TCCP's objectives were "to establish the means by which the civil engineering profession will be able to properly utilize the impact of the electronic computer and its related software in civil engineering practice, research and education." The first twelve TCCP chairs were: Robert L. Schiffman, Elias C. Tonias, Robert C. Y. Young, Augustine J. Fredrich, Norman R. Grieve, Steven J. Fenves, Vincent J. Vitagliano, Charles V. Smith, J. Crozier Brown, Charles Hodge, Morton B. Lipetz and Richard L. Bland.

Five sets of early activities of TCCP are worth singling out.

First, the Computer Practices Committee (CPC) produced an ASCE Manual on Computer Pricing [Branch 73, Computer 76] and a number of reports on professional issues. Building on activities started in 1971, CPC cooperated with CEPA and later with IUG on three projects:

- Sponsoring an NSF-funded Special Workshop on Engineering Software Coordination (1971) [Schiffman 72a, 72b, 72c];

- Conducting an NSF-funded study entitled "Definition of a National Effort to Promote Effective Application of Computer Software in the Practice of Civil Engineering and Building Construction" (1973-76) [CEPA 75; McGrory et al. 75]; and,

- Incorporating the National Institute for Computers in Engineering (NICE) "to provide an information service which will assist in promoting the effective use of computers and software as tools of the practicing engineer" (1980-82) [Computer 81].

The latter effort, important as it was for its time, came to naught with the advent of the personal computer and the subsequent blossoming of a competitive free-enterprise market in engineering software.

Second, starting with the $1^{\text {st }}$ Conference on Computing in Civil Engineering at Atlanta in June 1978s, (organized by Lipetz, Vitagliano and Leroy Z. Emkin), the Committee on Coordination Outside ASCE (COCOA) became the organizer of National Conferences and later Congresses on Computing In Civil Engineering. The first three Conferences were organized in conjunction and cooperation with CEPA and the ICES Users Group.

Third, COCOA organized the first International Conference, while the following three were organized by other groups. Eventually, COCOA took over the organization of the fifth International Conference and became instrumental in forming an organization that would oversee subsequent International Conferences. That organization, the International Society for Computing in Civil and Structural Engineering (ISCCSE), came into being in 1993 and was formally ratified in 1995. All International Conferences since that date have been conducted under the auspices of ISCCSE.

Over a span of 22 years, from 1978 to 2000, a total of 21 National and International Conferences and Congresses were sponsored. These conferences covered the entire range of computing topics throughout civil engineering. At a number of conferences entire tracks of sessions were devoted to special topics and were separately identified as symposia. Admittedly, at later 
Conferences and Congresses the coverage of the computing practices track has often not been as extensive as that of the academically oriented research track, and the two tracks have not always been well integrated. Nevertheless these Conferences and Congresses have become one of the preeminent media for the exchange of information on the rapidly evolving aspects of computing in civil engineering. Details regarding the national and international Conferences and Congresses are presented in Appendices B and C respectively.

Fourth, the Publications Committee undertook an aggressive publication schedule from the start, initially publishing in the Journal of the Technical Councils, then in the Journal of Technical Topics, and eventually in the Journal of Computing in Civil Engineering. These activities are detailed in Sections 5.1 and 5.2.

Fifth, the State of Computer Practices Committee (SOCP) responded to the perceived lack of information about practice-oriented information on computing available to ASCE members by launching the CE Computing Review newsletter, described in Section 5.3.

\subsubsection{Current Committee Activities}

In 1997 the Technical Council on Computer Practices (TCCP) officially became the Technical Council on Computing and Information Technology (TCCIT). Its committees, and their purpose, as stated in the official ASCE register, are as follows [ASCE 00].

Education: to study and promote educational uses of computers in the field of civil engineering; to promote the exchange of information regarding computer methods; to recommend those computer-related activities that promote educational objectives of colleges and universities.

Publications: to administer the solicitation, review, and editing of manuscripts submitted for publication in the JCCE (Section 5.0 discusses journals in greater detail).

Imaging Technologies: to coordinate and promote the exchange of technical information about current and emerging imaging technologies and their application to civil engineering problems and projects.

Intelligent Computing: to gather, maintain, and disseminate information on the application of expert systems and artificial intelligence to civil engineering, and to keep the Society membership aware of developments in this rapidly growing field.

State of Computer Practices: to gather, maintain, and disseminate information on existing and new developments in computer technology as it relates to civil engineering, and to promote an understanding within the engineering community of the benefits and limitations of that technology.

Database and Information Management: to increase the appropriate use of databases and information management technologies in civil engineering teaching 
and practice. Included in the committee scope are the representation, management, storage, and retrieval of civil engineering information, product and process modeling, data/object/knowledge repositories and interoperability standards, and information infrastructure issues.

Coordination of Computing Activities: to promote computer-related activities through coordination with groups internal and external to ASCE including presentation of specialty conferences and joint meetings with other organizations.

Activities undertaken by these committees vary widely and include: committee meetings, international and inter-organizational meetings; surveys; workshops; special issues and sections of the journal; conferences and conference sessions, tracks, and panels; as well as special publications and manuals.

\subsubsection{Education Surveys}

Adequate computing resources, expertise in the teaching of computing, and computing requirements in the curriculum have been concerns in engineering education by both the academic and professional communities. To a large extent the first two of these have been ameliorated over time. The third, however, still presents a dilemma to engineering education. To better understand these concerns and the steps to be taken to overcome them, the TCCP undertook a series of computing surveys in 1986, 1989, and 1995. Consideration is currently being given to a follow-up survey in 2001 .

In 1986 the Education Committee of the TCCP conducted a survey to determine the availability of computing resources in Civil Engineering Departments and to determine the attitude of faculty (and professionals) towards education in computing in civil engineering. The following specific areas that needed exposure were identified by the survey:

1) the technology of computers,

2) computers as problem solving tools, and

3) computers as engineering simulators to assist in design.

In 1987 TCCP formed a task committee to conduct a second survey to assess the status of computing in the civil engineering curriculum and to determine how to address these key areas. The task committee conducted the survey, analyzed and presented the results, suggested three different scenarios for incorporating problem solving computing tools and concepts into the curriculum, and enumerated lists of pros and cons for each scenario. The results of the work were published in [Law, et. al. 89, 90a, 90b] and were distributed widely to engineering faculty. Today they serve as a benchmark from which we can measure progress, reassess needs, and plan for the continued future roles of ASCE in computing in civil engineering [O'Neill 96a].

In 1995 the TCCP Education Committee again conducted a survey, aimed at both educators and practitioners, to determine their perspectives on the then current role of computing in civil engineering. Because of the steady improvements and advances in computer technology, the committee made the case that surveys must be repeated on a regular basis to ensure that the 
computing needs of the profession are being properly defined and met, and that curriculum changes can be made when appropriate [O'Neill 96a, 96b].

The results of the 1995 practitioners' survey were surprisingly close to those of the 1989 survey, with the 7 highest ranked items from 1989 (CADD, spreadsheets, databases, programming, graphics, word processing, and expert systems) appearing in the list of 9 ranked items in 1995. The new survey also identified the growing importance of the Internet by including communications in its top 9 items, whereas this item was ranked $11^{\text {th }}$ in 1989 [O'Neill 96a]. The results of the 1995 educators' survey were also close to the those of the 1989 survey, with 6 of the 8 highest ranked items from 1989 (spreadsheets, word processing, CAD, programming, databases, and expert systems) appearing in the list of 9 ranked items in 1995. There is also close agreement between the practitioner and academic surveys, indicating broad agreement on computing skill needs.

However, the 1995 survey clearly indicated that academicians had still not reached a consensus on what to teach with respect to a programming language course [O'Neill 96b]. It was also observed that there was no consensus definition for computer fluency, a constantly moving target. Finally, the results of the survey indicated a strong appreciation for advances in information technology (communications and the Internet), as well as for the use of computing to assist students in communicating their ideas (equation solvers and presentation software) [O'Neill 96b].

\section{PUBLICATIONS}

A number of ASCE publications have contributed to the advancement of computing in civil engineering. These include its archival journals, special journal issues, conference proceedings, special publications, and textbooks. Some of its conventional publications such as ASCE Magazine and ASCE News publish feature articles on computing in civil engineering. These and other publications are described in this section.

\subsection{Journal of Technical Councils/Topics}

When the Technical Council on Computer Practices was established in 1973, it had no immediate outlet for information dissemination through publications. For the 14 years between 1973 and 1987 the Publications Committee of TCCP worked first through the Journal of the Technical Councils (JTC) and then through the Journal of Technical Topics (JTT) to publish research findings and results.

In 1977 ASCE first published the JTC for the purpose of presenting the research activities of the Technical Councils. The JTC was published aperiodically from 1977 through 1982 (Volume 103, Number TC1, December 1977 through Volume 108, Number TC2, November 1982).

In 1983 the JTC of ASCE became the JTT in Civil Engineering. It was then published aperiodically through December of 1985 (Volume 109, Number 1, April 1983 through Volume 111, Number 1, December 1985). At that time ASCE split the content of the JTT, establishing individual journals for each of the Councils. Thus, the first issue of the JCCE appeared in 1987 
(Volume 1 Number 1, January 1987), establishing the one primary archival publication of the TCCP.

\subsection{Journal of Computing in Civil Engineering}

The goal of the JCCE is to serve as an archival resource on computing in civil engineering for the professional and academic communities alike. It is published four times a year. The Journal is abstracted in ASCE Publications Information, Transactions of ASCE, and in the Civil Engineering Database (online). It is indexed in the ASCE Annual Combined Index and the Science Citation Index. The Journal covers new programming paradigms, information management systems, computer aided engineering, intelligent computing, robotics and automation, and implementation strategies, as well as organizational impacts of and for computing resources.

\subsubsection{Five Year Review}

All journals of ASCE are periodically evaluated for quality assurance. The JCCE underwent such a 5-year review for the period of 1990 through 1994. [Lakmazaheri 95, 96] Although the review contained some of the elements of "what the journals contain" its primary focus was on "what people think of the journal." Insights into this question were gained through surveys of reviewers and authors, readers, and previous subscribers.

One of the findings of the 5-year review was that the quality and scope of the journal was satisfactory. Another key finding was that the majority of those responding to the survey indicated that the JCCE did not influence their professional practice; these readers viewed the papers as too theoretical and suggested that the balance between research and practice was unsatisfactory. On the other hand, the needs of the academic community for a society publishing outlet in computing in civil engineering which would provide for a forum of information exchange on research and education topics, act as a resource for graduate teaching and research, and act as a filter to evaluate the degree of success, applicability or utility of new computer science concepts and methodologies applied to civil engineering, were perceived as being successfully met.

\subsubsection{Ten Year Analysis}

A 1997 study provided a window on computing in civil engineering through the eyes of the JCCE [Lakmazaheri 97, 98]. That study conducted a detailed analysis of the journal over the 10year period from 1987 to 1996, the first decade of publication.

The analysis was made to obtain a general perspective on the contributions and technical content of the journal. Its purpose was to help the computing in civil engineering community gain a better understanding of the nature and dynamics of: (1) the research community and research areas and topics; and (2) the literature forming the knowledge infrastructure of the published work. The study tabulated: authors and their contribution patterns; computing topics and civil engineering sub-disciplines covered; and references cited, categorized (journals, conferences, reports, and theses), and their sources tabulated. 
This study resulted in a valuable compilation of information. The study did not draw conclusions but it provided a wealth of information regarding the publication of knowledge about computing in civil engineering. The report highlighted the significant role of ASCE in the advancement of computing in civil engineering through the JCCE.

\subsection{CE Computing Review}

By 1989, TCCIT's State of Computer Practices Committee (SOCP) was increasingly concerned about how to get information about practice-related computing in civil engineering to ASCE's membership. About the same time, the Society's Publications department was pursuing several options for creating new breeds of periodicals including discipline-specific newsletters. SOCP agreed that a newsletter would fit its goals and in June of 1989, CE Computing Review published its first monthly issue. CE Computing Review was edited by a professional editor employed by the Society's Publications department. SOCP provided the majority of the newsletter's editorial board. Articles were submitted to the editor and, although often reviewed by the editorial board, the final decision on publication was made by the editor.

CE Computing Review's content explored several avenues with emphasis on computer use by practicing civil engineers. There were several reviews of popular Civil Engineering software products written by engineers who used the products. The newsletter also provided basic personal computer user topics; at the time this was the only place that many ASCE members were exposed to such information. During the life of CE Computing Review, SOCP continued to provide technical assistance and aid to the editors in creating a popular periodical. Many of the articles written for the newsletter were authored by SOCP committee members. Two SOCP members, Tracy W. Lenocker and Charles S. Hodge, authored monthly columns for several years for the newsletter.

During its first three years, CE Computing Review was financially successful in that its subscription fees offset the cost of the editor, publishing and mailing. In the following two years, the newsletter did not break even and became a financial burden on the Society. Its last issue was published in June 1994.

\subsection{Other ASCE Publications}

ASCE Journals have sponsored a number of special issues or sections directly or indirectly focused on computing in civil engineering. Appendix D provides a compilation of these and identifies the theme, subject, or title of the special issue, as well as the journal sponsoring it. These special issues and sections provide insight into computing areas deemed to be timely and of interest to the readers of various civil engineering sub-disciplines. There is emphasis on topics broadly grouped into artificial intelligence (expert systems, robotics, neural networks, and even IVHS) and information technology (databases, object-oriented systems, GIS, and data, product, and process modeling).

Civil Engineering Magazine devotes a full issue of feature articles to computing each year, usually in June. Individual articles in other issues, such as [Dewberry 00], focus on the application of computing or new automation technologies in the practice of civil engineering. 
Each issue of the magazine features a section on Software Reviews and a computing section that focuses on the web, software, and hardware. As a service to Society members, each issue also contains a significant amount of advertisement related to computing in civil engineering.

The Society sponsors a web page. This site assists civil engineers by providing information of interest to the profession. Additionally, the site supports activities of the Publications Division through a database of publications information.

The Civil Engineering DataBase, a comprehensive electronic index that presently contains all articles published in all 28 ASCE Journals from the present back to 1973, provides a variety of indexes and information access formats. Conference proceedings papers, ASCE Press books, standards, committee reports, manuals of practice, and Civil Engineering Magazine have also been added to the database. Finally, an active forward link to the actual text of the article has been added for all on line journals.

Beginning in January 1999 full text versions of all ASCE Journals appeared on line, providing direct access to the text of the articles. Furthermore, the ASCE references cited in an article point to their citation in the Civil Engineering DataBase. Thus, each article points to all of its ASCE references and any ASCE journal reference (since January 1999) points to the actual text of the article it cites.

On the horizon are two additional on line capabilities to be offered by ASCE. The first is the Virtual Journal. The Virtual Journal focuses on a timely topic of interest in a specialized area. An ASCE editor selects articles from all 28 journals that relate to the topic and synthesizes them into a virtual journal, which points to each article in its home journal. The second is the Personal Journal. A reader subscribes to a fixed number of articles per year, rather than to one or more entire journals, and may search the entire journals database and extract or download up to the specified number of articles from any of the journals.

\section{SUMMARY AND OBSERVATIONS}

In the first two decades of the "computer era", emphasis on computing in civil engineering was dispersed between organizations outside ASCE, notably computer user groups, and committees within ASCE divisions which addressed computing as a component of the sub-disciplines within each division's scope. Of these committees, the Committee on Electronic Computation of the Structural Division had the most ambitious program of publications and conferences. However, as modern methods of structural analysis became more general, much of the literature in the field moved out of ASCE publications into journals with broader scope. Thus, ASCE publications did not, and could not, become the premier archival repository on, say, the finite element method. Furthermore, the segmentation of ASCE into divisions precluded any organizational entity that could address computing issues across the breadth of the profession.

At the end of this formative period, the Technical Council on Computer Practices emerged in response to the need for addressing within ASCE a range of broad professional issues arising out of the increased use of computing. The TCCP also pointed the way for ASCE to form other 
councils dealing with cross-disciplinary issues. In many respects, TCCP, together with its successor TCCIT, have satisfied the objectives of the initial petitioners, in at least two respects.

First, TCCP provided the ASCE "seal of approval" on publications dealing with professional issues such as computer pricing policies at a time where such a seal was needed. Most of these issues have by now become so much a part of civil engineering business practices that the ASCE seal is no longer needed.

Second, the TCCP publications and proceedings of conferences and congresses have provided a forum for the discussion and dissemination of innovations in computing in civil engineering. The record is by no means perfect. As the surveys indicate, the practice-oriented segment of the Society feels poorly served by the JCCE, but this is a perennial issue across all ASCE publications. The conference and congress proceedings have a larger contingent of practiceoriented material, but here too research themes predominate. This is not a bad thing by itself; after all, today's research is the seed of tomorrow's practice. What makes the situation in computing in civil engineering more precarious is the extremely rapid changes in computing and IT. Much of computing in civil engineering research is motivated by the perceived shortcomings in practice. However, with very few exceptions, the vast effort by the civil engineering industry organizations and software vendors has taken place with essentially no direct input from the research community. The best that can be said is that practice has benefited from some of the research explorations that have produced awareness and illustrations of new approaches.

In parallel with TCCP, the institutes, divisions and councils of ASCE have continued a deep involvement with computing in civil engineering, which now permeates every aspect of the profession. This frequently raises the question on where a new paper is to be published or the search for a prior paper initiated: is the content more clearly identified by the kind of computing involved or with the sub-discipline specific phenomenon addressed. This overlap, and potential abuses of it, requires the vigilance of all journal editors and conference program chairmen.

Finally, ASCE as a whole has continued to adapt aspects of computing in civil engineering through its magazine and other IT initiatives. 


\section{REFERENCES}

ASCE. (2000). "Official Register," American Society of Civil Engineers, Reston, VA.

Archer, J. S. (August 1963). "Consistent Mass Matrix for Distributed Mass Systems," Journal of the Structural Division, American Society of Civil Engineers, Volume 89, Number ST4 (Proceedings of the Third Conference on Electronic Computation, Boulder, Colorado, June 1921, 1963), Pages 161-178.

Branch, R. E., (Chairman). (1973). "Computer Pricing Practices," Manual and Report, Second Edition, Computer Practices Committee, Technical Council on Computer Practices, American Society of Civil Engineers, Number 59.

CEPA Newsletters. (October 1966 - August 1975). "Civil Engineering Program Applications," CEPA.

CEPA, Inc. (October 1975). "A Proposal for a National Institute for Computers in Engineering."

Clough, R.W. (November 1958). "Structural Analysis by Means of a Matrix Algebra Program," Proceedings of the First Conference on Electronic Computation, American Society of Civil Engineers, Kansas City, MO, Pages 109-132.

Clough, R.W. (September 8-9, 1960). "The Finite Element Method in Plane Stress Analysis," Proceedings of the Second Conference on Electric Computation, American Society of Civil Engineers, Pittsburgh, PA, Pages 345-378.

Computer Practices Committee, Technical Council on Computer Practices. (October 1976). "Computer Pricing Policy and Methods," Engineering Issues - Journal of Professional Activities, Proceedings of the American Society of Civil Engineers, Volume 102, Number EI4, Pages 437446.

Computer Practices Committee, Technical Council on Computer Practices. (April 1981). "Business Plan for the Establishment of National Institute for Computers in Engineering (NICE)," Journal of the Technical Councils, American Society of Civil Engineers, Volume 107, Number TC1, Pages 169-189.

Dewberry, S. O. (September 2000). "Easing the Way for E-Permitting," Civil Engineering, American Society of Civil Engineers, Volume 70, Number 9, Pages 54-57.

Fenves, S. J., et al. (1965). "STRESS: A Reference Manual," M. I. T. Press, Cambridge, Massachusetts.

Fenves, S. J., et al. (1964). "STRESS: A User's Manual," M. I. T. Press, Cambridge, Massachusetts. 
Lakmazaheri, S. and Rasdorf, W.J. (January 1998). "Foundation for Research in Computing in Civil Engineering," Journal of Computing in Civil Engineering, American Society of Civil Engineers, Volume 12, Number 1, Pages 9-18.

Lakmazaheri, S. and Rasdorf, W.J. (September 1997). "The First 10 Years: A Foundation for Research in Computing in Civil Engineering," Technical Report, American Society of Civil Engineers.

Lakmazaheri, S. and Rasdorf, W.J. (April 1996). "A Review and Assessment of the Journal of Computing in Civil Engineering," Journal of Computing in Civil Engineering, Editorial, American Society of Civil Engineers, Volume 10, Number 2, Pages 95-96. [five year REVIEW]

Lakmazaheri, S. and Rasdorf, W.J. (December 1995). "Contents Review of the Journal of Computing in Civil Engineering," Technical Report, American Society of Civil Engineers.

Law, K. H., Rasdorf, W. J., Karamouz, M. and Abudayyeh, O. Y. (April 1990). "Computing in the Civil Engineering Curriculum: Needs and Issues," Journal of Professional Issues in Engineering, American Society of Civil Engineers, Volume 116, Number 2, Pages 128-141.

Law, K. H., Rasdorf, W. J., Karamouz, M. and Abudayyeh, O. Y. (September 1989). "The Role of Computing in Civil Engineering Education," Proceedings of the Sixth Conference on Computing in Civil Engineering, American Society of Civil Engineers, Atlanta, GA, Pages 442450.

Law, K. H., Rasdorf, W. J., Karamouz, M. and Abudayyeh, O. Y. (April 1990). "The Role of Computing in the Civil Engineering Curriculum," Proceedings of the ASCE 1990 National Forum on Education and Continuing Professional Development for the Civil Engineer, American Society of Civil Engineers, Las Vegas, NE, Pages 337-343.

Logcher, R.D., et. al. (September 1965). "A User's Manual for On-Line Use of the Structural Design Language," Project MAC Memorandum M-234, Massachusetts Institute of Technology, Cambridge, MA.

McGrory, H. M. et al. (November 1975). "The National Software Center", Preprint 2626, ASCE National Convention Meeting.

Miller, C.L. (August 1961). "COGO-A Computer Programming System for Civil Engineering Problems," Technical Report, Department of Civil Engineering, Massachusetts Institute of Technology, Cambridge, MA.

Miller, C.L. (August 1963). "Man-Machine Communication in Civil Engineering," Journal of the Structural Division, American Society of Civil Engineers, Volume 89, Number ST4 (Proceedings of the Third Conference on Electronic Computation, Boulder, Colorado, June 1921, 1963), Pages 5-30. 
O'Neill, R. J., Henry, R. M. and Lenox, T. A. (June 1996). "Role of Computing: Practitioners' Perspective," Proceedings of the Third Congress on Computing in Civil Engineering, American Society of Civil Engineers, Anaheim, CA, Pages 670-676.

O'Neill, R. J., Henry, R. M. and Lenox, T. A. (June 1996). "Role of Computing: Educators' Perspective," Proceedings of the ASEE Annual Conference, American Society for Engineering Education, Washington D.C., Session 3215.

Rasdorf W.J. (January 1997). "Journal of Computing in Civil Engineering: Editorials," Technical Report, Department of Civil Engineering, North Carolina State University, Raleigh, NC.

Roesett, J., et. al. (September 1965). "Highway Bridges and Structures Bridge Design System," Technical Report R65-26, Department of Civil Engineering, Massachusetts Institute of Technology, Cambridge, MA.

Roos, D. (1967). "ICES System Design," MIT Press, Cambridge, MA, (1966), $2^{\text {nd }}$ Edition.

Roos, D. and Miller, C.L. (April 1964). "COGO-90: Engineering User's Manual," Technical Report R64-12, Department of Civil Engineering, Massachusetts Institute of Technology, Cambridge, MA.

Schiffman, R. L. (March 1972). "Report on the Special Workshop on Engineering Software Coordination," Computer Center Report 72-2, University of Colorado, Boulder, CO.

Schiffman, R. L. (April 1972). "Papers Prepared for the Special Workshop on Engineering Software Coordination," Computing Center Report 72-4, University of Colorado, Boulder, CO.

Schiffman, R. L. (June 1972). "Transcript of the Special Workshop on Engineering Software Coordination," Computing Center Report 72-17, University of Colorado, Boulder, CO. 


\section{APPENDIX A: Conferences on Electronic Computation and Analysis and Computation}

In the table a dash is used to indicate information that is not available. All entries in the document column represent conference proceedings except for four, which were published in the journals noted. The asterisk denotes the Library of Congress Catalog Card Number. The first 10 conferences were referred to as Conferences on Electric Computation. Presently and including $11,12,13$, and 14 the conferences are referred to as Conferences on Analysis and Computation.

\begin{tabular}{|c|c|c|c|c|c|c|}
\hline Number & Date & Location & Document & Editor & Library \#* & ISBN \# \\
\hline $1^{\text {st }}$ & $11 / 20-11 / 21 / 58$ & Kansas City, MO & -- & -- & -- & -- \\
$2^{\text {nd }}$ & $9 / 8-9 / 9 / 60$ & Pittsburgh, PA & - & -- & -- \\
$3^{\text {rd }}$ & $6 / 19-6 / 21 / 63$ & Boulder, CO & $(89)$ ST4,8/63 & -- & -- \\
$4^{\text {th }}$ & $9 / 7-9 / 9 / 66$ & Los Angeles, CA & $(92)$ ST6,12/66 & -- & -- \\
$5^{\text {th }}$ & $8 / 31-9 / 2 / 70$ & Lafayette, LA & $(97)$ ST1,1/71 & -- & -- \\
$6^{\text {th }}$ & $8 / 7-8 / 9 / 74$ & Atlanta, GA & $(101)$ ST4,4/74 & -- & -- \\
$7^{\text {th }}$ & $8 / 6-8 / 8 / 79$ & St. Louis, MO & -- & -- & -- & - \\
$8^{\text {th }}$ & $2 / 21-2 / 23 / 83$ & Houston, TX & -- & James K. Nelson Jr. & $59-65010$ & $0-87262-351-3$ \\
$9^{\text {th }}$ & $2 / 23-2 / 26 / 86$ & Birmingham, AL & -- & Kenneth M. Will & $85-73831$ & $0-87262-512-5$ \\
$10^{\text {th }}$ & $4 / 29-5 / 1 / 91$ & Indianapolis, IA & -- & Oktay Ural and Ton-Lo Wang & $91-12684$ & $0-87262-802-7$ \\
& & & & & \\
$11^{\text {th }}$ & $4 / 24-4 / 28 / 94$ & Atlanta, GA & -- & Franklin Y. Cheng & $94-7104$ & $0-87262-974-0$ \\
$12^{\text {th }}$ & $4 / 15-4 / 18 / 96$ & Chicago, IL & -- & Franklin Y. Cheng & $96-11789$ & $0-7844-0163-2$ \\
$13^{\text {th }}$ & $7 / 19-7 / 23 / 98$ & San Francisco, CA & -- & N. K. Srivastava & -- & $0-08-042845-2$ \\
$14^{\text {th }}$ & 2000 & Philadelphia, PA & -- & -- & \\
\hline
\end{tabular}




\section{APPENDIX B: National Conferences on Computing in Civil Engineering}

\begin{tabular}{|c|c|c|c|c|c|}
\hline Number & Date & Location & Editor(s) & Library \#* & ISBN \# \\
\hline $1^{\text {st }}$ & $6 / 26-6 / 29 / 78$ & Atlanta, GA & Morton B. Lipetz and Leroy Z. Emkin & -- & -- \\
$2^{\text {nd }}$ & $6 / 9-6 / 13 / 80$ & Baltimore, MD & David R. Schelling & $80-66141$ & $0-87262-246-0$ \\
$3^{\text {rd }}$ & $4 / 2-4 / 6 / 84$ & San Diego, CA & Charles S. Hodge & $80-66141$ & $0-87262-396-3$ \\
$4^{\text {th }}$ & $10 / 27-10 / 31 / 86$ & Boston, MA & W. Tracy Lenocker & $86-25911$ & $0-87262-569-9$ \\
$5^{\text {th }}$ & $3 / 29-3 / 31 / 88$ & Alexandria, VA & Kenneth M. Will & $88-3771$ & $0-87262-635-0$ \\
$6^{\text {th }}$ & $9 / 11-9 / 13 / 89$ & Atlanta, GA & Thomas O. Barnwell Jr. & $89-37697$ & $0-87262-722-5$ \\
$7^{\text {th }}$ & $5 / 6-5 / 8 / 91$ & Washington, DC & Louis F. Cohn and William J. Rasdorf & $91-12813$ & $0-87262-803-5$ \\
$8^{\text {th }}$ & $6 / 7-6 / 9 / 92$ & Dallas, TX & Barry J. Goodno and Jeff R. Wright & $92-13050$ & $0-87262-869-8$ \\
\hline
\end{tabular}

\section{National Congresses on Computing in Civil Engineering}

\begin{tabular}{|c|c|c|c|c|c|}
\hline Number & Date & City & Editor(s) & Library \#* & ISBN \# \\
\hline $1^{\text {st }}$ & $6 / 20-6 / 22 / 94$ & Washington, DC & Khalil Khozemieh & $94-19972$ & $0-7844-0026-1$ \\
$2^{\text {nd }}$ & $6 / 5-6 / 8 / 95$ & Atlanta, GA & J. P. Mohsen & $95-15012$ & $0-7844-0088-1$ \\
$3^{\text {rd }}$ & $6 / 17-6 / 19 / 96$ & Anaheim, CA & Jorge Venegas and Paul Chinowsky & $96-19480$ & $0-7844-0182-9$ \\
$4^{\text {th }}$ & $6 / 16-6 / 18 / 97$ & Philadelphia, PA & Teresa M. Adams & -- & $0-784-0250-7$ \\
$5^{\text {th }}$ & $10 / 18-10 / 21 / 98$ & Boston, MA & Kelvin C. P. Wang & & $0-784-0381-3$ \\
\hline
\end{tabular}




\section{APPENDIX C: International Conferences on Computing in Civil Engineering}

\begin{tabular}{|c|c|c|c|c|c|}
\hline Number & Date & Location & Country & Library \#* & ISBN \# \\
\hline $1^{\text {st }}$ & $5 / 12-5 / 14 / 81$ & New York, NY & USA & $81-66346$ & $0-87262-270-3$ \\
$2^{\text {nd }}$ & 1985 & Hangzhou, Zhegjiang & China & $4950-61 * *$ & $0-444-99560-9$ \\
$3^{\text {rd }}$ & $8 / 10-8 / 12 / 88$ & Vancouver, BC & Canada & -- & -- \\
$4^{\text {th }}$ & 1991 & Tokyo & Japan & -- & -- \\
$5^{\text {th }}$ & $6 / 1-6 / 9 / 93$ & Anaheim, CA & USA & $93-17524$ & $0-87262-915-5$ \\
$6^{\text {th }}$ & 1995 & Berlin & Germany & -- & 9054105569 \\
$7^{\text {th }}$ & 1997 & Seoul & Korea & -- & \\
$8^{\text {th }}$ & $8 / 14-8 / 16 / 00$ & Stanford, CA & USA & -- & $0-7844-0513-1$ \\
\hline
\end{tabular}

** Science Press Book No.

\section{APPENDIX D: Journal Special Issues and Sections}

\begin{tabular}{|c|c|c|c|l|}
\hline Journal & Issue & Date & Category & \multicolumn{1}{c|}{ Subject } \\
\hline JCEM & V119 N2 & June, 93 & Issue & "Applications of Microcomputers and Workstations in Construction" \\
& & & & \\
JTE & V113 N2 & March, 87 & Section & "Use of Expert Systems in Transportation Engineering" \\
JTE & V113 N4 & July, 87 & Issue & "Microcomputers in Transportation" \\
JTE & V116 N3 & May/June, 90 & Section & "Robotics and Automatic Imaging in Transportation Engineering" \\
JTE & V116 N4 & July/August, 90 & Section & "Intelligent Vehicle/Highway Systems" \\
& & & & \\
JCCE & V1 N4 & October, 87 & Issue & "Expert Systems in Civil Engineering" \\
JCCE & V4 N3 & July, 90 & Section & "Computational Geometry" \\
JCCE & V5 N1 & January, 91 & Section & "Expert Systems in Planning and Design" \\
JCCE & V6 N1 & January, 92 & Issue & "Databases" \\
JCCE & V6 N3 & July, 92 & Issue & "Object Oriented Systems" \\
JCCE & V7 N3 & July, 93 & Issue & "Geographic Information Analysis" \\
JCCE & V8 N2 & April, 94 & Issue & "Neural Networks" \\
JCCE & V8 N4 & October, 94 & Issue & "European Computing" \\
JCCE & V10 N3 & July, 96 & Section & "Data, Product, and Process Modeling" \\
JCCE & V13 N1 & January, 99 & Issue & "Computing and Information Technology in AEC Education" \\
JCCE & V13 N2 & April, 99 & Issue & "Imaging Technologies in Civil and Environmental Engineering" \\
JCCE & V15 N1 & January, 01 & Issue & "Information Technology for Life Cycle Infrastructure Management \\
\hline
\end{tabular}

JCEM - Journal of Construction Engineering and Management

JTE - Journal of Transportation Engineering

JCCE - Journal of Computing in Civil Engineering 